\title{
VIABILIZANDO A GUARDA COMPARTILHADA ATRAVÉS DA MEDIAÇÃO DE CONFLITOS
}

\section{ARTIGO ORIGINAL}

ARRUDA, Emmanuelle Mayara Costa de Oliveira ${ }^{1}$

ARRUDA, Emmanuelle Mayara Costa de Oliveira. Viabilizando a guarda compartilhada através da mediação de conflitos. Revista Científica Multidisciplinar Núcleo do Conhecimento. Ano 05, Ed. 09, Vol. 02, pp. 68-84. Setembro de 2020. ISSN: 2448-0959,

Link de acesso: https://www.nucleodoconhecimento.com.br/lei/guarda-compartilhada

\section{RESUMO}

O artigo trata do estudo sobre a mediação de conflitos como instrumento na reorganização das relações familiares, após o rompimento da união conjugal, para a aplicação do modelo de guarda compartilhada, compreendido como uma proposta saudável de convivência parental. Propõe o compartilhamento de guarda à coparentalidade, bem como o exercício conjunto e colaborativo da responsabilidade pelos genitores sobre a prole. Contudo, a guarda compartilhada encontra dificuldades para sua implantação em ambiente onde há litigiosidade entre os ex-cônjuges. Emerge como ferramenta alternativa para o trato das divergências de ordem familiar, a mediação, lançando um novo olhar e pensar sobre o problema, a partir de um procedimento consensual, restabelecendo a interlocução entre os genitores e, conseqüentemente, facilitando a construção de acordos. Atuam a guarda compartilhada e a mediação de conflitos na efetivação do principio da dignidade da pessoa humana, como fundamento da família. Pretende-se assim, promover uma reflexão, a fim de que os operadores do direito, atuantes na área de família, despertem para o uso consciente da mediação, como método interdisciplinar disponível para a

\footnotetext{
${ }^{1}$ Pós-graduada em Psicologia jurídica e Graduada em Direito.
} 
pacificação das desavenças familiares, tornando possível a implementação da guarda compartilhada.

Palavras-chave: Guarda compartilhada, conflito, mediação.

\section{INTRODUÇÃO}

Na década de 1960 houve o surgimento da metodologia da guarda compartilhada na Inglaterra, sendo assim, recentemente, implementada em vários outros países. A realização desta modalidade foi desenvolvida a partir de um problema causado pela guarda unilateral, visto que havia uma possível injustiça, por causa da desigualdade de tratamentos dos pais sobre os seus filhos, uma vez que a guarda fosse imposta somente para uma dessas figuras parentais. Dito isso, através da guarda compartilhada foi possível atribuir a ambos os pais o dever de educação e cuidado perante crianças e adolescentes (MOREIRA, 2014; ALVARENGA e CLARISMAR, 2015).

No Brasil, partindo do princípio de isonomia entre homens e mulheres, a guarda compartilhada foi estabelecida devido as transformações familiares contemporâneas, buscando a maior participação dos pais não-guardiões, através das reivindicações realizadas por estes, com o melhor interesse da criança (ALVES; ARPINI e CUNICO, 2015; DIAS, 2015; ROSA, 2015). De acordo com alguns doutrinadores essa modalidade traria a possibilidade de igualar os papéis parentais na garantia de que sejam supridas as necessidades afetivas e emocionais dos filhos após o rompimento conjugal.

Em conformidade com Oliveira (2012), a guarda compartilhada corresponde a uma concepção jurídica que propõe a equivalência no exercício da autoridade parental, bem como a responsabilização conjunta dos pais para a assistência e educação dos filhos, nos casos de quebra da célula familiar. Visa o instituto do compartilhamento de guarda a manutenção das relações afetivas para a continuidade dos laços paternofiliais, com fim no desenvolvimento salutar dos filhos menores. A problemática gira em torno do impasse que a guarda compartilhada vem encontrando para a sua concreta 
aplicação, quando entre os genitores do menor existem conflitos que dificultam o diálogo sobre os interesses da prole, tornando assim a medida implantada inócua, em situações de hostilidade.

Os problemas de ordem familiar carregam em si uma densa carga emocional, não encontrando a atenção devida quando transformados em litígios processuais. O modelo adversarial, o qual se assenta o Poder Judiciário, intensifica por vezes a contenda entre os genitores, insuflando a disputa de poder entre o "ganhar" e "perder" a guarda dos filhos (OLIVEIRA, 2012). Nesse diapasão, a mediação emerge como uma ferramenta alternativa, propondo uma nova visão do conflito, necessário para o amadurecimento humano, conduzindo-o por um procedimento consensual, que facilita a desobstrução do canal de comunicação, favorecendo conseqüentemente, uma composição entre os genitores dentro das possibilidades de cada um, no bem-estar dos filhos.

\section{UM NOVO MODELO DE GUARDA: RESPONSABILIDADE PARENTAL E CONVIVÊNCIA FAMILIAR}

A Lei ํo 11.698 de 13 de junho de 2008, decretada pelo Congresso Nacional e sancionada pelo Presidente da República, institui e disciplina a guarda compartilhada, alterando os artigos 1.583 e 1.584 da Lei no 10.406, de 10 de janeiro de 2002 - Código Civil.

A partir da leitura do $\S 1^{\circ}$, art. 1.583 do Código Civil, compreende-se:

Art. 1.583. [...] omissis

$\S 1^{\circ}$. [...] por guarda compartilhada a responsabilização conjunta e o exercício de direitos e deveres do pai e da mãe que não vivam sob o mesmo teto, concernentes ao poder familiar dos filhos comuns.

O direito de família não poderia se furtar diante das nuances que tomam forma na estrutura familiar, buscando então, adequar-se às novas configurações, possibilitando no cerne do conflito parental a proteção dos filhos com a aplicação e efetivação do modelo de guarda compartilhada. 
As diversas legislações, internacionais e nacionais (Convenção dos Direitos da Criança, Constituição Federal de 1988, Estatuto da Criança e do Adolescente), funcionam como instrumentos protetivos dos interesses do menor, tanto dentro da estrutura social da qual este faz parte, como no próprio seio familiar. Tais legislações partem do pressuposto que a garantia do desenvolvimento normal e saudável de uma criança ou adolescente, inicia-se dentro da estrutura familiar basilar. Sendo assim, é necessário garantir dentro de um processo de dissolução conjugal, o equilíbrio das relações que se formaram (OLIVEIRA, 2012).

O novo instituto da guarda compartilhada propõe a efetivação dos princípios ligados ao bem-estar do menor num processo de separação judicial, abrindo a possibilidade de permanência dos laços afetivos numa família dissociada. Com o rompimento da sociedade conjugal a questão da guarda entra em discussão e, na maioria dos casos, é afetada pelos sentimentos consequentes da dissolução, prejudicando o reconhecimento das necessidades dos filhos que agora precisam se adaptar à nova formatação da família.

A guarda compartilhada chama os pais para exercerem conjuntamente a responsabilidade que possuem sobre os filhos, procurando atenuar os efeitos negativos da separação no relacionamento paterno-filial. Com a aplicação do modelo de guarda compartilhada, visa-se a continuidade das relações estabelecidas na constância da união conjugal, com a equivalência da autoridade parental no fim da formação biopsicossocial dos filhos (GRISARD, 2000)

Vale salientar que, embora a guarda compartilhada seja o modelo preferencial, cabe ao magistrado, em cada caso, avaliar a viabilidade da sua aplicação, sempre no melhor interesse da criança e do adolescente. Para a sua concessão são necessários alguns requisitos, sejam eles, respeito mútuo, capacidade colaborativa, flexibilidade, disponibilidade física e afetiva e, se possível, residência próxima. Para Grisard (2000, p.168) a guarda compartilhada:

[...] eleva o grau de satisfação de pais e filhos e elimina os conflitos de lealdade, ou seja, a necessidade de escolher entre seus dois pais, enquanto os filhos querem estar ligados aos dois genitores. E ficam 
profundamente aflitos quando precisam escolher um ou outro. A guarda eleva os padrões éticos dos pais, cuja criança sempre deve ser ouvida. Os juízes costumam ouvir o menor, sem exigir que faça a escolha, pois as crianças não querem responder a pergunta sobre com quem gostariam de morar, porque sabem da mágoa que podem causar ao outro genitor.

A guarda compartilhada proporciona ao pai ou a mãe, que não possuem mais a ligação conjugal, apresentando ambos a vontade, bem como as condições necessárias de seguir criando os filhos, exercerem solidariamente a responsabilidade sobre estes, participando ativamente do dia-a-dia do menor para preservação e fortalecimento dos vínculos de afeto e afinidade. Neste sentido, ambos os pais participarão na tomada de decisões importantes acerca dos filhos, no que concerne a escolha do médico, escola, atividades de lazer, entre outras.

Sobre a participação dos pais na vida dos filhos assevera Lôbo (2008, p. 176):

A guarda compartilhada é caracterizada pela manutenção responsável e solidária dos direitos-deveres inerentes ao poder familiar, minimizandose os efeitos da separação dos pais. Assim, preferencialmente, os pais permanecem com as mesmas divisões de tarefas que mantinham quando conviviam, acompanhando conjuntamente a formação e o desenvolvimento do filho. Nesse sentido, na medida das possibilidades de cada um, devem participar das atividades de estudos, de esporte e de lazer do filho. O ponto mais importante é a convivência compartilhada, pois o filho deve sentir-se „em casa" tanto na residência de um quanto na do outro.

A aplicação da guarda compartilhada propõe a aproximação do pai e da mãe na relação peterno-filial, estreitando as relações familiares, construídas com base no amor, afeto, solidariedade, comunhão de interesses, para o bem-estar dos filhos, como também dos demais membros da família. Silva (2008), afirma que o modelo de compartilhamento de guarda possibilita 0 não sobrecarregamento das responsabilidades dos genitores, uma vez que a autoridade parental, bem como os cuidados de assistência e educação com os filhos serão igualmente exercidos.

Com relação aos benefícios proporcionados aos menores pela guarda em compartilhamento, a psicologia contemporânea afirma que a presença de ambos os genitores participando na vida dos filhos é de extrema relevância para a formação da 
personalidade da criança e do adolescente. Neste norte afirma Silva (2008), que há estudos comprovados de que crianças envolvidas em guarda compartilhada apresentam um grau mais elelvado de desenvolvimento psicoemocional, se comparado com aquelas que se interagem a maior parte do tempo com apenas um desses genitores. São elas mais calmas e pacientes.

Em suma, a lei da guarda compartilhada trouxe alteração no que concerne: necessidade do juiz da causa em informar aos genitores sobre as vantagens do modelo de compartilhamento de guarda, até mesmo antes de homologar a conciliação; promoção da co-responsabilidade no exercício do poder familiar; efetivação do princípio da igualdade entre homens e mulheres na prática da parentalidade; consagração como modelo preferencial e, por fim, o estabelecimento de sanção por descumprimento imotivado da cláusula de guarda, podendo reduzir o tempo do genitor desidioso de convivência com o filho (OLIVEIRA, 2012).

Por fim, conforme Oliveira (2012), o modelo de compartilhamento pode ser um instrumento eficaz utilizado para evitar o conflito entre os pais sobre a guarda dos filhos, incentivando o consenso do casal na busca do melhor interesse para o menor, a partir da construção de relações harmoniosas e colaborativas. Como alternativa para efetivação da guarda compartilhada em casos de conflito, pode-se aplicar o método da mediação familiar.

\section{O CONFLITO COMO IMPASSE PARA A GUARDA COMPARTILHADA}

Desde a entrada em vigor da Lei oㅜ 11.698/08, o modelo de compartilhamento vem encontrando dificuldades para a sua aplicação em ambiente hostil, onde há conflito entre os genitores sobre a guarda dos filhos. Os operadores do direito que se opõe à guarda compartilhada, diante da existência de litígio entre o casal, afirmam que poderá ocorrer a frustração da medida bem como o comprometimento do melhor interesse do menor, quando não há entendimento entre os cônjuges. 
Nesse sentido, expõe Silva (2008, p. 162), o conflito como uma das desvantagens da guarda compartilhada:

Finalmente, sem duvida, o maior argumento contrario à guarda compartilhada é o que levanta a questão de que, na pratica, a guarda conjunta só funciona quando pais e mães se entendem. E, dizem seus opositores, não há o que se fazer a fim de que casais traumatizados por longos e dolorosos processos judiciais possam, de repente, conversar amigavelmente sobre os problemas dos filhos. Muitos advogados e magistrados ainda vêem a tese do compartilhamento com desconfiança, pois entendem que esse tipo de guarda dividira o mundo das crianças, principalmente quando os pais não morrem de amores, mas de ódio, um pelo outro.

Sendo assim, a guarda, seja esta única ou compartilhada, deverá ser estabelecida de acordo com a organização familiar, levando em consideração a estrutura de cada vínculo construído entre seus membros, visando o melhor interesse do menor. Após a dissolução conjugal, uma vez que o casal não consegue superar as desavenças, não será o modelo de guarda, aplicado em meio ao conflito, que irá restabelecer a harmonia familiar. Os problemas oriundos do rompimento da união influenciarão independente da guarda ser única ou compartilhada se não houver o tratamento necessário das questões familiares envolvidas (OLIVEIRA, 2012).

A guarda exclusiva aplicada preferencialmente ao modelo de compartilhamento, quando houver litígio conjugal, não faz cessar o conflito familiar. Poderá a guarda única gerar a insatisfação do genitor não guardião, bem como desencadear problemas que poderão obstruir os vínculos afetivos entre pais e filhos. Dessa forma, as discussões familiares perpetuam-se, malogrando qualquer espécie de guarda. Inadequado seria vincular a aplicação da guarda compartilhada ao bom entendimento entre os pais, uma vez que não existindo compreensão entre ambos, nenhum modelo funcionará. Desta maneira, as visitas não ocorreriam, a exemplo, no estabelecimento de guarda única, a partir das dificuldades postas pelo genitor guardião àquele que não possui a guarda como meio de atingi-lo pelo fracasso conjugal e conseqüente ressentimentos (FERREIRA, 2004). 
Para que ocorra a efetiva aplicação do instituto de compartilhamento, deverá haver a separação do casal conjugal do parental, a fim de minorar os efeitos da dissolução para os filhos e, no bem destes. Oliveira (2012) afirma que o modelo de guarda compartilhada coaduna-se nesse sentido, pois possibilita a cooperação entre os pais e a continuidade dos laços familiares, assinalando para os ex-cônjuges os direitos e deveres nas relações de filiação que permanecem mesmo após o rompimento da sociedade conjugal. A guarda compartilhada suplanta o conflito conjugal para o atendimento do melhor interesse dos filhos menores, conscientizando os pais da permanência necessária do casal parental no desenvolvimento saudável da criança e do adolescente.

Nesse sentido, afirma Brito (2005, p. 62),

[...] percebesse que manter a parentalidade exercida por pai e mãe após a separação pode ser um desafio com conflitos iniciais, mas a procura do equilíbrio é necessária para as crianças, sendo contra-indicado o abandono do conflito pelo afastamento compulsório, ou voluntário, de um dos pais.

A modificação trazida pela lei da guarda compartilhada gerou discussão sobre a preferência do modelo de compartilhamento de guarda sobre a exclusividade antes atribuída a quem revelasse melhores condições - guarda única.

$\mathrm{O} \S 2^{\circ}$, do art. 1.584 da lei em comento dispõe que, "quando não houver acordo entre a mãe e o pai quanto à guarda do filho, será aplicada, sempre que possível, a guarda compartilhada".

A partir da leitura do referido dispositivo, uma parcela da doutrina civilista alega que a aplicação da guarda compartilhada como modelo preferencial poderá prejudicar os filhos, quando existir conflito entre os cônjuges. Porém, a lei que institui o compartilhamento coaduna-se com o melhor interesse da criança e do adolescente, preservando-Ihes a convivência familiar como também o pleno desenvolvimento, a partir da continuidade dos vínculos parteno-filiais. O texto da lei tem papel regulador das relações familiares, reafirmando a dupla filiação e a participação conjunta dos pais na vida dos filhos. Os desentendimentos familiares não podem ser vistos como 
empecilhos para aplicação da guarda compartilhada, deve-se buscar superá-los por meios alternativos que proporcione a satisfação de todos os membros envolvidos no litígio, bem como o sucesso da medida, que visa sempre o melhor interesse dos filhos (FERREIRA, 2004).

\subsection{O PODER JUDICIÁRIO NA PACIFICAÇÃO DO LITÍGIO FAMILIAR}

Em conformidade com Oliveira (2012), diante do conflito familiar, vários casais não conseguem encontrar uma solução amigável para os seus desentendimentos. Os sentimentos envolvidos numa dissolução conjugal como a perda, mágoa, raiva, vingança, entre outros, minam os canais de comunicação entre o casal e a possibilidade de acordo entre ambos, colocando questões relevantes, como a guarda dos filhos, em segundo plano.

A responsabilidade pelo problema familiar e sua resolução são transferidos pelos excônjuges para as mãos do Estado, cabendo a este a decisão sobre aspectos importantes na vida dos membros do grupo. O procedimento legal torna-se necessidade para defesa e ataque pelo casal. Muito embora o sistema judicial se esforce para efetivação dos direitos fundamentais, dentro do cenário que apresenta uma nova configuração do direito de família, a aplicação da lei em alguns casos diverge do interesse do menor, bem como da particularidade de cada caso.

A lei da guarda compartilhada representou um avanço na legislação brasileira e uma vitória para as novas necessidades sociais. Porém, para sua real efetivação é preciso o amadurecimento de ideias e posturas que ainda encontram resistência diante de padrões tradicionais. Brito (2012), explana que dificuldade para a aplicação do modelo de guarda compartilhada emerge também do tratamento dado pelo poder judiciário ao conflito de família. O processo civil utilizado possui uma lógica binária, identificando a parte vencedora e perdedora da ação. O procedimento jurídico mostra-se inadequado para a solução do litígio familiar, uma vez que reforça a disputa entre o casal. 
De acordo com Koerner (2002, p. 43), o poder judiciário está organizado para solucionar os conflitos baseado-se no modelo normativista e individualista. Explica ainda o autor,

O modelo individualista e adversarial supõe que, para a sua resolução, o conflito deve ser transformado em processo ou litígio judicial, no qual os envolvidos são representados como partes individuais que defendem seus interesses antagônicos perante um terceiro neutro, o juiz. $O$ processo judicial se desenrola de acordo com procedimentos formalizados, em que as partes têm a oportunidade de apresentar suas pretensões e os dispositivos jurídicos que lhes dão apoio, bem como as suas respectivas versões dos fatos e os elementos probatórios que permitem reconstituí-los. Cada parte tem a oportunidade de contestar a versão apresentada pela outra e reforçar seus próprios argumento [...]

Vale salientar ainda, a morosidade do aparelho jurídico brasileiro, bem como o desgaste de cada parte envolvida no litígio processual diante de um sistema burocrático e dispendioso. Nesse norte, o modelo adversarial proposto mostra-se inadequado para o trato do conflito de família. Formas alternativas de solução de conflitos devem ser buscadas e incentivadas pelo próprio poder judiciário, não como forma de substituí-lo, porém de auxiliá-lo em assuntos que exigem um maior cuidado e sensibilidade, o que não se observa nas questões de família levadas ao tribunal (OLIVEIRA, 2012).

Nesse diapasão, surge a mediação familiar, uma vertente da mediação, considerada mais adequada para solução do conflito. Busca a mediação, trazer os cônjuges para dentro do processo de tomada de decisões sobre os seus próprios problemas proporcionando o enfrentamento democrático da crise familiar. A mediação familiar poderá gera nos envolvidos a satisfação pelo acordo, a elevação da auto-estima, minoração dos traumas pela dissolução, bem como evita o surgimento de conflitos futuros, uma vez que trata do litígio familiar com suas nuances e não de forma superficial (FERREIRA, 2004). 


\section{PROCEDIMENTO DA MEDIAÇÃO DE CONFLITOS}

O conflito surge naturalmente a partir da divergência de interesses entre indivíduos, alterando o equilíbrio das relações intersubjetivas. A dificuldade está em encontrar o modo adequado para o trato da desavença, possibilitando a minoração dos efeitos da peleja sobre a relação, bem como satisfazendo o anseio de cada parte. Afirma Vicente (2000, p. 54),

O modo de lidar com os problemas pode ser também democrático e de respeito pelas diferenças, e mesmo de valorização da crise, quando o modo preferencial de lidar com as dificuldades é pelo entendimento, pela linguagem, pela conversa.

A mediação é um instrumento disponível para a dissolução do conflito que emerge das relações construídas, propondo uma nova compreensão da crise, esta vista como uma oportunidade de amadurecimento e adaptação às mudanças ocorridas.

Sobre a abordagem do conflito na mediação assevera Groeninga (1999, apud SILVA, 2008, p. 167),

[...] portanto, dependendo de nossa visão do conflito daremos a este um tratamento diferente, assim como disto também dependerá nosso posicionamento em relação ao sofrimento que se nos apresenta. A formação em Mediação permite o conhecimento dos vários níveis, formas e limites em abordar o conflito e com isto uma maior abrangência, menos reducionismo e possibilidade de cronificação. Permite também o reconhecimento de suas possibilidades transformadoras.

O trabalho desenvolvido pela mediação possibilita a explanação do conflito com suas peculiaridades, a partir de uma visão humanizada do problema apresentado pelos mediandos, sendo visto cada caso de forma singular e tratado de acordo com as necessidades de cada envolvido. A mediação de conflitos mostra-se também como um recurso alternativo ao modelo conflitual, desenvolvido tradicionalmente pelo Poder Judiciário, para dirimir as contendas, respeitando a individualidade dos envolvidos, como também admitindo a existência de diferenças, tratadas pelo diálogo democrático entre as partes. (MORAIS, 2001; SPENGLER, 2008) 
Para Warat (2001), a mediação é uma maneira "ecológica de resolução dos conflitos sociais e jurídicos, uma forma na qual o intuito de satisfação do desejo substitui a aplicação coercitiva e terceirizada de uma sanção legal."

O processo de mediação é informal, podendo ocorrer de forma extra ou judicialmente, anterior ou mesmo no curso da demanda, suspendendo o processo. O procedimento de mediação não apresenta modelo definitivo, podendo variar de acordo com a matéria abordada, uma vez que a mediação é instrumento utilizado nas relações intersubjetivas, como também nas relações entre indivíduos e instituições.

A mediação poderá ser utilizada como instrumento na pacificação de controvérsias em diversas áreas. Existe a mediação penal, realizada entre a vítima e o agressor para o restabelecimento da justiça; mediação educativa ou nas escolas; a mediação desenvolvida em instituições de saúde; em contendas sobre o meio ambiente; nas desavenças comunitárias; nas organizações e no trabalho; conflitos políticos e familiares. Neste ultimo observa-se a relevância da mediação como meio mais adequado devido às peculiaridades dos conflitos de família (FERREIRA, 2004).

Ainda segundo Ferreira (2004), ao primeiro contato com os interessados denominase pré-mediação. Na pré-mediação o mediador informa às partes sobre o processo de mediação, os objetivos e regras, o papel do profissional, realiza a escuta de cada parte e fecha o contrato, este último se tratar-se de mediação extrajudicial. No processo de mediação, o mediador irá auxiliar os mediandos a definirem o conflito, conscientizando-os dos limites do problema para que encontrem pontos de convergência e percebam que a crise que estão enfrentando pode ser resolvida em benefício de ambos.

Em concordância com Oliveira (2012), a partir da identificação dos pontos conflitantes, o mediador com as informações obtidas irá auxiliar os envolvidos a buscarem opções de acordo, proporcionando uma visão do conflito que facilite a composição. Quando a matéria da mediação versar sobre separação, assuntos sobre bens, guarda, pensão, serão discutidos ponto a ponto. Realizado o acordo, este é redigido de forma clara e simples, sendo assinado pelo mediador e mediados. Poderá ser levado para 
homologação judicial. Em algumas matérias com interesses relevantes é necessária a manifestação do Ministério Público.

A mediação proporciona a (re) abertura da interlocução entre os membros da família, incentivando à solidariedade, compreensão, respeito. Possibilita o reconhecimento do outro como sujeito, possuidor de defeitos e fragilidades. As partes se vêem como aliadas para o bem e preservação da família, colaborando para que haja um ganho mútuo, existindo apenas vencedor-vencedor, substituindo à dinâmica adversarial que insufla o conflito (SALES, 2004).

O diálogo estimulado entre os envolvidos, auxiliados pelo mediador, busca a compreensão e delimitação do problema prevenindo sua superdimensão. Os conflitos familiares por envolverem uma gama de sentimentos geralmente têm suas causas camufladas ou superestimadas. São denominados de conflitos aparentes, uma vez que não exprime a veracidade dos problemas. De acordo com Sales (2004), os conflitos reais, geralmente mascarados, e os aparentes, são evidenciados na mediação.

\section{A MEDIAÇÃO COMO INSTRUMENTO DE VIABILIZAÇÃO DA GUARDA COMPARTILHADA}

Segundo Ferreira (2004), os conflitos familiares transformados em disputas judiciais envolvem uma complexidade de questões surgindo assim à necessidade de um trabalho interdisciplinar dentro da estrutura do poder judiciário. São profissionais, a exemplo de assistentes sociais e psicólogos que auxiliam o juiz de direito na busca da verdade real dos fatos para aplicação adequada da lei ao caso concreto.

Muito embora a intervenção dos referidos profissionais adentre no âmbito relacional dos membros da família, bem como avalie os sentimentos envolvidos nos vínculos construídos, não há o tratamento do conflito familiar com suas causas e conseqüências.A sentença proferida no processo judicial, apesar de possuir efeito e teoricamente acalmar os ânimos das partes envolvidas não significa, em alguns casos, a solução do conflito familiar, uma vez que este vem sendo alimentado bem 
antes da demanda intentada (SALES, 2004). Nesse contexto de incapacidade e inadequação do poder judiciário no trato das relações familiares, surge a necessidade do instrumento de mediação, considerado uma forma menos traumática para lidar com os conflitos de família. Revela-se também importante a mediação pelas novas formas de família que surgem depois da dissolução conjugal.

A mediação familiar é um instrumento disponível para auxiliar os pais na aceitação e aplicação do modelo de guarda compartilhada após a dissolução conjugal, constituindo-se uma proposta saudável de convivência entre os pais e filhos, como também para o exercício conjunto da responsabilidade parental. Como dito alhures, a critica quanto à aplicação do modelo de compartilhamento de guarda está no sentido da medida caracteriza-se inviável e ineficaz em ambiente de litigiosidade.

Sobre a importância da mediação para a efetiva aplicação da guarda compartilhada, Silva (2008, p. 171) comenta:

Como a maior desvantagem da aplicação da guarda compartilhada, conforme rebatem seus opositores, é a falta de dialogo entre os pais, ainda ressentidos e portadores de rancor pelo fracasso do casamento, fato esse que impediria qualquer possibilidade de atuação conjunta do poder familiar, sem dúvida a mediação se torna um caminho a ser pelo menos tentado, para restabelecer a comunicação entre eles, essencial para que continuem a atuar não mais como esposos, mas como pais que serão para sempre.

Para Oliveira (2012), o trabalho da mediação familiar está focado no melhor interesse da criança e do adolescente, propondo a reorganização das relações familiares, após a ruptura da célula conjugal. O tratamento do conflito, bem como a prevenção de contendas futuras a partir da facilitação do diálogo entre os genitores, possibilitará o exercício concreto da guarda compartilhada no bem dos filhos menores. Conscientizados e redirecionados os pais para suas responsabilidades poderão estes trabalhar em conjunto na educação e cuidado com os filhos, exercendo de forma plena a autoridade parental como também o direito constitucional à convivência familiar.

A mediação não dispensa a figura do juiz quando feita judicialmente. É um parêntese no processo de guarda provocando a suspensão do processo. A interação entre o juiz 
da causa com uma equipe multidisciplinar, conjugando varias áreas do saber, está centrada na pacificação do conflito familiar e no melhor interesse dos filhos.

Nesse sentido Lôbo (2008, p. 177) afirma,

Para o sucesso da guarda compartilhada é necessário o trabalho conjunto do juiz e das equipes multidisciplinares das Varas de Família, para o convencimento dos pais e para a superação de seus conflitos. Sem um mínimo de entendimento a guarda compartilhada pode não contemplar o melhor interesse do filho [...]. O uso da mediação é valioso para o bom resultado da guarda compartilhada, como tem demonstrado sua aplicação no Brasil e no estrangeiro [...]. Sob o ponto de vista dos princípios constitucionais do melhor interesse da criança e da convivência familiar, a guarda compartilhada é indiscutivelmente a modalidade que melhor os realiza.

Salienta-se ainda que, a mediação não é uma solução mágica, porém é considerada mais adequada por possuir facilitadores no restabelecimento da harmonia familiar.

A lei sobre guarda compartilhada prevê em seu § $3^{\circ}$, do art. 1.584 a mediação interdisciplinar dispondo,

\section{Art. 1.584. [...] omissis}

$\S 3$ ‥ Para estabelecer as atribuições do pai e da mãe e os períodos de convivência sob a guarda compartilhada, o juiz, de oficio ou a requerimento do Ministério Público, poderá basear-se em orientação técnico-profissional ou equipe interdisciplinar.

Diante da permissão legal expressa na Lei ํo 11.698/08, vê-se a possibilidade de utilização do instrumento de mediação familiar para a aplicação efetiva da guarda compartilhada, nos casos de ruptura conjugal, tratando o conflito existente que dificulta o exercício da responsabilidade conjunta pelos pais e convivência familiar destes com os filhos menores. Atenta-se por fim, para a necessidade de reflexão, a fim de que os operadores do direito, atuantes na área de família, despertem para o uso consciente da mediação, como método interdisciplinar disponível para a pacificação das desavenças familiares, tornando possível a implementação da guarda compartilhada. 


\section{CONSIDERAÇÕES FINAIS}

Observa-se que a ruptura conjugal cria uma nova estrutura familiar, exigindo dos membros do grupo uma adaptação. A situação dos filhos carece de atenção face ao desenlace, sendo imprescindível que os pais prossigam no desempenho dos papéis parentais para o desenvolvimento integral daqueles. Faz-se necessário que os genitores mantenham a mesma postura de quando a família permanecia unida, quanto aos filhos, agindo de forma concorrente na assistência e educação da prole. Consubstancia-se nesse sentido, a guarda compartilhada, que propõe a paridade na qualidade do convívio entre pais e filhos nos casos de família descomposta.

A guarda compartilhada coaduna-se com a contemporânea configuração familiar, que valoriza os vínculos de afeto e afinidade que unem os membros do núcleo. Fundamenta-se o modelo de compartilhamento na valorização da família, como espaço privilegiado para a manifestação de sentimentos, realização pessoal de cada indivíduo, bem como para formação deste nas suas relações intersubjetivas em comunidade na condição de ator social.

O instituto da guarda compartilhada prestigia o melhor interesse da criança e do adolescente, com fins na sua formação física e mental completa, a partir do apoio oferecido pelos genitores. Isto gera no menor a sensação de proteção e felicidade, ao ver a interação de ambos preocupados com o seu bem maior, minimizando os efeitos negativos advindos da dissolução conjugal. A guarda compartilhada possibilita a permanência dos laços parentais, oferecendo de forma criativa uma divisão mais equilibrada do tempo de contato entre pais e filhos. A criança ou o adolescente possuirá tanto o referencial materno quanto o paterno necessários para sua construção. Tais vantagens serão dificilmente identificadas na guarda unilateral, a qual favorece a posição do genitor guardião, enfraquecendo a relação do filho com o outro genitor, que atua de forma contida no exercício do poder familiar.

Saliente-se ainda para a compatibilidade da espécie de guarda compartilhada com o princípio de igualdade entre os cônjuges na sociedade conjugal, mesmo após o seu término, revelados na Constituição Federal de 1988. Para que a guarda compartilhada 
funcione com todas as suas benesses é preciso que os genitores sobreponham as necessidades dos filhos aos conflitos de conjugalidade, exercendo de forma responsável a parentalidade. Nesse esteio, apresenta-se a mediação como ferramenta que poderá auxiliar os casais que se separam ou divorciam a encontrarem soluções adequadas para a nova formatação familiar.

A compreensão dada pela mediação ao problema de família favorece a constatação pelos ex-cônjuges das suas reais intenções, superando as dificuldades da dissociação. O diálogo usado como técnica permite a discussão das desavenças de maneira democrática, permitindo o encontro de pontos de contato que possibilitem a construção de acordos pelos próprios mediandos. A mediação estimula a composição pacífica do conflito familiar, a partir do contexto colaborativo, no qual estão inseridos os mediandos, aliados para atuação conjunta da autoridade parental, bem como para a assunção das responsabilidades derivadas do papel de mãe e pai que nunca deixarão de existir. Postura que não se observa na estrutura do Poder Judiciário, que se baseia no modelo adversarial, pondo os conflitantes em lados opostos, asseverando por vezes as divergências.

O acordo, como conseqüência do procedimento mediativo, é fruto da parceria entre os envolvidos, auxiliados pelo mediador, terceiro neutro que não emite juízo valorativo sobre o caso, não julga "certo" ou "errado", nem aponta "vencedor" e "perdedor", apenas ajuda os mediandos a valorizarem os pontos positivos que possuem para atingirem uma composição dentro das possibilidades de cada um. O mediador é pessoa imparcial que realiza uma escuta qualificada na condução da mediação. Sendo os mediados responsáveis pela tomada de decisão, os acordos acabam por serem mais exequíveis e possíveis desentendimentos futuros são evitados.

A utilização da mediação no trato dos conflitos familiares, de forma a dissolvê- los, possibilita o conseqüente equilíbrio das relações de família, viabilizando a aplicação da guarda compartilhada como medida que atende ao superior interesse dos filhos. Torna-se necessário que, os meios alternativos de resolução de conflitos sejam estimulados para a garantia de acesso à justiça, esta entendida aqui em seu sentido amplo. A humanização das contendas postas para decisão do Poder Judiciário 
deverá ser algo a ser perquirido também, principalmente no que se refere aos problemas de ordem familiar, eivados de uma subjetividade muitas vezes não compreendida ou mal interpretada pelo magistrado.

O Direito não poderá se furtar diante das mutações sociais, como também das transformações que ocorrem no seio familiar, ficando tolhido a ultrapassados métodos jurídicos descompassados com 0 atual contexto. A guarda compartilhada e a mediação de conflitos correspondem às novas exigências da sociedade e da família, necessitando ambos os institutos de estudos mais detalhados e despidos de preconceitos, pondo fim as dúvidas que existam sobre as suas aplicações.

\section{REFERÊNCIAS}

ALVARENGA, A. R.; CLARISMAR, J. (2015). Sistemas de guarda no direito brasileiro. Revista do Curso Direito UNIFOR, MG, 6(1), 12-27.

ALVES, A. P., ARPINI, D. A.; CÚNICO, S. D. (2015). Guarda compartilhada: perspectivas e desafios diante da responsabilidade parental. Estudos e Pesquisa em Psicologia, 15(3), 916-935.

ANDRADE, Gustavo Henrique Baptista. Sobre a mediação familiar. Disponível em:<http://www.ibdfam.org.br/?artigos\&artigo=515>. Acesso em: 12 ago. 2020.

BRASIL. Lei no 11.698, de 13 de junho de 2008. Altera os arts. 1.583 e 1.584 da lei no 10.406, de 10 de janeiro de 2002 - código civil, para instituir e disciplinar a guarda compartilhada. Disponível em: <http://www.planalto.gov.br/ccivil_03/_Ato20072010/2008/Lei/L11698.htm.>. Acesso em: 12 ago.2020

. Lei $n^{\circ} 10.406$ de 10 de janeiro de 2002. Novo código civil. Disponível em:<http://www.planalto.gov.br/CCIVIL/leis/2002/L10406.htm>. Acesso em: 15 dez. 2020.

. Câmara dos Deputados. Projeto de lei no 4.827, de 10 de novembro de 1998. Institucionaliza e disciplina a mediação, como método de prevenção e solução 
consensual

de

conflitos.

Disponível em:

$<$

http://www.camara.gov.br/proposicoesWeb/fichadetramitacao?idProposicao=21158.

>. Acesso em: 23 fev. 2020.

BRITO, Leila Maria Torraca de. Guarda compartilhada: um passaporte para a convivência familiar. In: APASE - Associação de pais e mães separados (Org.). Guarda compartilhada: aspectos psicológicos e jurídicos. Porto Alegre: Equilíbrio, 2005.

FERREIRA, Verônica A. de Motta Cezar. Família, separação e mediação: uma visão psicojurídica. São Paulo: Método, 2004.

FILHO, Waldir Grisard. Guarda compartilhada: um novo modelo de responsabilidade parental. São Paulo: Revista dos tribunais, 2000.

KOERNER, Andrei. Justiça consensual e conflitos de família: algumas reflexões. In: Marcelo Lábaki Agostinho; Tatiana Maria Sanchez (Org.). Família: conflitos, reflexões e intervenções. São Paulo: Casa do Psicólogo, 2002.

LOBO, Paulo Luiz Netto. 1 ed. Direito civil: famílias. São Paulo: Saraiva, 2008, vol. 1 MORAIS, SPENGLER, Fabiana Marion. Mediação e arbitragem. Alternativas à jurisdição. 2 ed. rev., ampl. Porto Alegre: Livraria do Advogado, 2008.

OLIVEIRA, Emmanuele Mayara Costa de. Viabilizando a Guarda Compartilhada através da Mediação de Conflitos, João Pessoa, 2012.

SALES, Lília Maia de Morais. Mediare: um guia prático para mediadores. Fortaleza: PROCURADORIA DE JUSTIÇA do Estado do Ceará, 2004.

SILVA, Ana Maria Milano. A lei sobre guarda compartilhada. Leme: J.H. Mizuno, 2008. 
VICENTE, Cenise Monte. O direito à convivência familiar e comunitária: uma política de manutenção do vínculo. In: Sílvio Manoug Kalaustian (Org.). Família brasileira, a base de tudo. 4 ed. São Paulo: Cortez; Brasília, DF: UNICEF, 2000

Enviado: Setembro, 2020.

Aprovado: Setembro, 2020. 